\title{
El Mercadeo Directo ${ }^{1}$
}

M.E. Swisher and James Sterns ${ }^{2}$

\section{¿Qué es el Mercadeo Directo?}

Se puede definir el mercadeo directo como la venta directa del productor al consumidor, pero esta definición sencilla no toma en cuenta la importancia de las relaciones personales involucradas en estos intercambios. El desarrollo de vías de mercadeo director es una fuente de relaciones entre individuos, agricultores y consumidores, las cuales crean uniones no solamente comerciales sino sociales. La venta directa más común es cara a cara, en un mercado del agricultor, por ejemplo. Sin embargo, actualmente se está desarrollando el mercadeo directo por medio del Internet.

\section{¿Cuáles son las Diferencias Entre el Mercadeo Directo y el Mercadeo Tradicional?}

La meta del mercadeo tradicional es vender el producto al por mayor en grandes cantidades. Es el volumen del producto vendido que sostiene los ingresos del agricultor; generalmente el precio por unidad es bajo. Muchas veces, el comprador se preocupa principalmente por conseguir el producto más barato. Se asume, en general, que todos los productos de la misma clase son idénticas - un tomate de clase una es igual a cualquier otro tomate de la misma clase. Como resultado, el agricultor no tiene que preocuparse mucho por distinguir su producto de aquel de otros productores.

Al contrario, el mercadeo directo se enfoquen en las diferencias entre productos y especialmente en las características específicas de los productos de cada agricultor. El pasar del mercadeo tradicional al mercadeo directo requiere un cambio mental fundamental por parte del agricultor. Para lograr éxito en la venta directa, el agricultor tiene que reconocer que ni todos los productos ni todos los consumidores son iguales. Los consumidores tienen preferencias y gustos muy particulares y la meta del agricultor es producir una variedad de productos que pudiesen satisfacer los gustos de los diferentes clientes. El agricultor que aprovecha de las diferencias entre consumidores en lugar de ignorarlas no tiene que competir para producir el producto más barato.

\section{¿Cómo los Pequeños Productores Pueden Aprovechar del Mercadeo Directo?}

Generalmente los pequeños productores no son competitivos en los mercados tradicionales. Para lograr tener el producto más barato, un agricultor tiene que tener los costos de producción más bajos.

1. This document is FCS7211-Span, one of a series of the Department of Family, Youth and Community Sciences, Florida Cooperative Extension Service, IFAS, University of Florida, Gainesville FL 32611: First published: September 2003. English version reviewed by Millie Ferrer, Associate Professor and Amy Simmone Assistant Professor, Department of Family, Youth and Community Sciences, Cooperative Extension Service, Institute of Food and Agricultural Sciences, University of Florida, Gainesville, 32611. Please visit the EDIS Web site at http://edis.ifas.ufl.edu

2. M.E. Swisher, Ph.D., Associate Professor, Department of Family, Youth and Community Sciences and James Sterns, Assistant Professor, Food and Resource Economics, University of Florida, Gainesville FL 32611. 
Los grandes agricultores, quienes pueden comprar insumos en cantidades, producen mucho volumen a poco costo relativo. Por lo tanto, son las fuentes preferidas por los grandes compradores de productos agrícolas.

Aunque el pequeño productor no puede competir con el grande en cuanto al precio de sus productos, estos negocios familiares tienen particularidades que les dan ventajas cuando se tratan de otras calidades del producto, y no sólo el precio. El agricultor que quiere aprovechar del mercadeo directo tiene que ofrecer a sus clientes algo diferente - un producto que no se puede comprar en el supermercado ó un producto con una característica ausente en el mismo producto comprado en el supermercado.

Un producto conveniente. Las ensaladas pre-mezcladas son un ejemplo de un producto muy conveniente para el consumidor. Muchos productores pequeños venden mezclas de diferentes tipos de lechuga, listas para la mesa. Otros agricultores incluyen recetas con sus productos, especialmente recetas rápidas y fáciles de preparar, para hacer más fácil la preparación por el consumidor.

EI sabor. Muchos consumidores dicen que el sabor y la frescura de los productos comprados directamente del agricultor son las razones principales para sus compras. El productor que vende sus productos el mismo día que se cosechan siempre puede ofrecer el producto más fresco y sabroso al cliente. Los pequeños productores también pueden prestar más atención a cada fruta ó verdura, seleccionando solamente aquellas maduras de buen sabor.

Variedad. El pequeño productor no tiene que especializarse en la producción de un sólo cultivo. Puede producir muchos tipos de tomates, por ejemplo, incluyendo variedades antiguas de buen sabor que no se pueden almacenar para mucho tiempo. Estas variedades no se encuentran en los supermercados. También pueden producir muchos cultivos diferentes, incluso animales, en la misma finca y así ofrecer al consumidor un rango amplio de productos distintos.

Novedad. Los pequeños productores también tienen el lujo de experimentar con cultivos diferentes y nuevos. Como el pequeño agricultor no tiene que sembrar cientos de acres en un sólo cultivo, puede ensayar la producción de cultivos no tradicionales.

Tipo de Producción. Actualmente, más y más consumidores están dispuestos a pagar un precio elevado para productos procedentes de sistemas de producción que protegen al ambiente. La vente de productos orgánicos, por ejemplo, aumenta más de un 20 por ciento por año. Otros ejemplos son la producción pecuaria al pastoreo, la producción "ecológica” y la producción local misma. El agricultor que toma en cuenta las preocupaciones y preferencias ideológicas del consumidor gana este "voto con el dólar."

\section{¿Cuáles son los Alternativos Para el Pequeño Productor?}

Hay muchas vías del mercadeo directo disponible al pequeño productor. Cada método tiene sus ventajas y desventajas y el agricultor tiene que escoger aquel que le sirve mejor, tomando en cuenta la situación específica de su finca. Una combinación de métodos es la mejor opción para muchos agricultores. Unos de los principales canales de mercadeo directo son:

- U-pick (cosecha por el consumidor)

- Tienda de carretera

- Mercado del agricultor

- Mercado comunitario

- Mercado comercial 
- Maestros de cocina y restaurantes

- Internet ó venta por correo

- Mercadeo cooperativo

- Cooperativa del consumidor

- Venta por Subscripción

- Venta institucional

Lo siguiente señala algunos de las ventajas y de los retos asociados con ocho de estas opciones.

U-Pick - el consumidor mismo cosecha el cultivo

\section{Ventajas}

- Ningún costo de cosecha

- Ningún costo de transporte

- No hay intermediario

- No se importa mucho la mezcla de cultivos o productos en la finca

\section{Retos}

- La localidad de la finca es crítica

- Responsabilidad legal para los clientes mientras están en la finca

- Importunidad en la vida familiar

- Estacionamiento

- Necesidad de estar presente en la finca para muchas horas

- Potencial de crecimiento limitado

- Poco valor agregado

Tienda de Carretera - una sencilla tienda al borde de la carretera, generalmente especializada en productos frescos

\section{Ventajas}

- No hay intermediarios

- Nadie viene a la finca

- Se puede conseguir productos de otras fincas para vender

- Estación alargada de venta, según los cultivos producidos ó disponibles

- Poco transporte

- Poco empaque

\section{Retos}

- La localidad de la tienda es crítica

- Mantenimiento de la tienda, buena presentación

- Necesidad de publicar la tienda

- Se necesita una buena variedad de productos; no se puede vender uno o dos

- Necesidad de mantener la tienda abierta para muchas horas diarias

- Estacionamiento 
Mercado del Agricultor - una feria ó mercado no permanente, generalmente estacional y abierto unos pocos días a la semana

\section{Ventajas}

- No hay intermediarios

- Nadie viene a la finca

- No se necesita una gran variedad de productos porque se complementan por los otros vendedores

- Cada vendedor aprovecha de la publicidad general para el mercado

- Se atraen muchos clientes potenciales

\section{Retos}

- El agricultor tiene que mantener contacto directo y amigable con los clientes

- Se puede gastar mucho tiempo en alistar los productos para el mercado y en el mercado mismo

- El empaque y la presentación general del producto es importante

- Distancia al mercado

- El costo de participar en el mercado

- Puede ser que el horario del mercado no le sirve, ni tampoco los meses cuando está abierto

- Hay competencia entre vendedores con los mismos productos ó productos parecidos

Internet ó Venta por Correo - el consumidor escoge y paga el producto por correo (antiguo sistema) o por el Internet y al agricultor se lo mande la compra

\section{Ventajas}

- Poca infraestructura requerida

- Nadie viene a la finca

- Horas muy flexibles

- Muchas oportunidades para crecimiento casi sin límite

\section{Retos}

- Diseñar y mantener una página en el Internet

- Se pierde la ventaja de la frescura de los productos locales

- Se requieren buenos programas de seguridad para aceptar pago electrónico

- Se requiere de muy buen empaque

- Costo, disponibilidad y constancia del transporte

Venta por Subscripción - el cliente paga en anticipación; en la forma más sencilla el cliente generalmente paga mensualmente ó cada 60 o 90 días para una cantidad fija de producto; en su forma más completa (CSA ó agricultor apoyado por la comunidad) el cliente paga anualmente y acepta el riesgo de no recibir una cantidad determinada de productos

\section{Ventajas}

- El pago en adelantado es una fuente de dinero en efectivo para el agricultor

- Los ingresos no dependen directamente del volumen de producto 
- El precio recibido por el producto no se determina por el precio en el mercado general

- Para el CSA, el agricultor comparte los riesgos con los clientes

- Para el CSA, se puede reducir la demanda para mano de obra si los miembros también trabajan en la finca

- Generalmente, los miembros mismos son la mejor fuente de publicidad

Mercadeo Cooperativo - una cooperativa de agricultores dedicada a la comercialización de los productos

\section{Ventajas}

- Mucho potencial para crecimiento

- Se combinan los recursos de muchos para hacer compras, la publicidad, el transporte, etc.

- Se logra una mejor variedad de productos que cualquier productor individual puede suplir

- Poca necesidad de infraestructura adicional en las fincas de los miembros

\section{Retos}

- Cada miembro es sujeto de las reglas y decisiones de la cooperativa; no se puede hacer decisiones individuales

- Cuesta mucho tiempo y bastante inversión inicial

- El manejo de la cooperativa es crítico; profesionales son preferibles

- La tendencia de desarrollar competencia entre miembros, especialmente la tendencia de algunos miembros de vender sus productos fuera de la cooperativa para aprovechar los precios altos

Mercado del Consumidor - los consumidores mismos desarrollan una tienda para los miembros y contratan con agricultores para suplir los productos vendidos

\section{Ventajas}

- Mercado estable sobre mucho tiempo

- Mucho potencial para crecimiento

- El agricultor recibe un alto porcentaje de precio recibido por el producto

- Poca inversión por el agricultor

\section{Retos}

- El apoyo activo de los consumidores es crítico; el agricultor tiene que desarrollar y mantener una relación positiva con los clientes

- Generalmente, los consumidores buscan una gran variedad de productos de muy alta calidad

- El manejo de la cooperativa es crítico; profesionales son preferibles

- Responsabilidades legales

- Es una organización formal, con reglas y estatutos, y se pueden desarrollar quejas

Venta Institucional - un agricultor ó, más comúnmente un grupo de agricultores, desarrollan contratos con instituciones públicas (escuelas, prisiones, etc.) ó privadas (hospitales, hogares para ancianos, compañías de cruceros, parques de atracción) y suplen productos especificados 


\section{Ventajas}

- Mercado estable, aunque generalmente es necesario renovar los contratos cada año

- Las instituciones hacen las compras con mucha anticipación (hasta un año), lo cual permite mejor planificación por el agricultor

- Alto potencial para crecimiento en Florida

\section{Retos}

- Se requiere bastante tiempo establecer contacto con los compradores para estas instituciones

- Hay reglas y normas para los productos en muchos casos

- Suministro regular y a tiempo es crítico; no se puede fallar en suplir el producto a tiempo

- Transporte es clave

- Se necesita un volumen amplio y consistente

\section{Cuatro Conceptos Básicos}

La información en esta sección de este boletín es un resumen y adaptación del folleto Keys to Success in Value Added Marketing por Holly Born. Esta publicación se produce por el Programa de Agricultura Sostenible del Departamento de Agricultura de los Estados Unidos (SARE) y la organización para la Transferencia de Tecnología Apropiada para Areas Rurales (ATTRA). La publicación completa se consigue sin costo de ATTRA ( http://attra.ncat.org ).

\section{Se necesita involucrar todos los accionistas}

Para lograr éxito en el mercadeo directo, el agricultor tiene que buscar el apoyo de lo demás. No se lo puede hacer sólo. No se olvida la importancia de conseguir el apoyo de los consumidores, otros agricultores, oficiales estatales y otros negocios. Utilice las habilidades y conocimiento de los otros. Pocos intentos de desarrollar el mercadeo directo por un sólo agricultor son exitosos.

\section{Es importante empezar pequeño y crecer sobre tiempo}

El mercadeo directo requiere de conceptos, prácticas y habilidades especiales y el agricultor tiene que adquirirlos, hasta los agricultores con mucha experiencia. Es importante desarrollar nuevas estrategias de mercadeo paso por paso, evaluando los resultados frecuentemente. El empezar en pequeña escala permite corregir problemas más fácilmente, sin la perdida de mayores inversiones de dinero y tiempo.

\section{Buenos datos son los fundamentos de buenas decisiones}

Se deben basar las decisiones en buenos datos. Aunque mantener los archivos no es una tarea muy agradable para la mayoría de personas, son críticos a la toma de decisiones. Es especialmente importante tener buenos datos durante períodos de cambio en su finca.

\section{Escuche los clientes}

Los clientes son la clave principal para la estrategia de mercadeo directo. El buen vendedor busca entender las opiniones, preferencias y gustos de sus clientes. Pero el entendimiento no es suficiente. Para lograr éxito, el agricultor tiene que ser dispuesto a hacer los cambios necesarios para suplir con los requisitos de sus clientes. 